\title{
A Study of Atmospheric Plasma Treatment on Surface Energetics of Carbon Fibers
}

\author{
Soo-Jin Park, ${ }^{*}$ Yong-Hwan Chang, ${ }^{\dagger}$ Cheol-Whan Moon, ${ }^{\ddagger}$ Dong-Hack Suh,${ }^{\dagger}$ Seung-Soon Im, ${ }^{\ddagger}$ and Yeong-Cheol Kim ${ }^{\S}$ \\ Deptartmemt of Chemistry, Inha University, Incheon 402-751, Korea. *E-mail: sjpark@inha.ac.kr \\ ${ }^{\dagger}$ Department of Chemical Engineering, Hanyang University, Seoul 133-791, Korea \\ *Division of Chemical Engineering, Hanyang University, Seoul 133-791, Korea \\ ${ }^{\S}$ Biorefinery Research Center, Korea Research Institute of Chemical Technology, Daejeon 305-600, Korea \\ Received July 6, 2009, Accepted December 21, 2009
}

\begin{abstract}
In this study, the atmospheric plasma treatment with $\mathrm{He} / \mathrm{O}_{2}$ was conducted to modify the surface chemistry of carbon fibers. The effects of plasma treatment parameters on the surface energetics of carbon fibers were experimentally investigated with respect to gas flow ratio, power intensity, and treatment time. Surface characteristics of the carbon fibers were determined by X-ray photoelectron spectroscopy (XPS), scanning electron microscope (SEM), Fourier transform infrared (FT-IR), Zeta-potential, and contact angle measurements. The results indicated that oxygen plasma treatment led to a large amount of reactive functional groups onto the fiber surface, and these groups can form together as physical intermolecular bonding to improve the surface wettability with a hydrophilic polymer matrix.
\end{abstract}

Key Words: Atmospheric plasma, Surface energetics, Carbon fibers, Plasma treatment

\section{Introduction}

Fiber-reinforced plastics are composite materials composed of heat hardening resin among new materials and are advanced composite materials with the matrix of epoxy resin that has relatively excellent chemical properties. Due to a number of advantageous characteristics, such as high strength, high toughness, good electrical conductivity, and light weight, carbon fibers are usually employed as a reinforcing agent in composite materials for a wide variety of applications. ${ }^{1-5}$ And the plasma is an efficient method in the field of surface modification and the surface of various materials can be readily modified using plasma. As nonaqueous surface modification processes, plasma treatments have been widely studied in the laboratory for improving wettability or hydrophilicity. However, most of the studies use vacuum systems that require an expensive and complicated vacuum environment. ${ }^{6-8}$ Therefore, much attention has been paid to plasmas operating at atmospheric pressure due to possible advantages of eliminating an expensive vacuum system, on-line processing capabilities, high efficiency, and the scalability to a large area. Atmospheric pressure plasma treatment does not require the complicated and expensive vacuum system, and there are few restrictions on the treated materials. Plasma generated by RF glow discharge at room temperature, as used in this study, contains free radicals, positive and negative ions, electrons, metastable molecules and UV radicals that have enough energy to break chemical bonds such as $\mathrm{C}-\mathrm{C}, \mathrm{C}-\mathrm{O}$ and $\mathrm{C}-\mathrm{H}$ in substrate materials. The relevant mechanism was explained in terms of reactions between radicals and oxygen gas. ${ }^{9}$ That is to say, the radicals, formed on carbon fiber surface by the highly energetic species in plasma, react with the supplied oxygen gas, resulting in the secondary formation of the characteristic surface functional groups such as - $\mathrm{OH}$, - $\mathrm{COOH}$, etc. It is used to produce special functional groups at the surface, increase the surface energy, increase or decrease hydrophilicity, improve chemical inertness, introduce cross-linking, remove weak boundary layers and con- tamination, and increase the surface morphology. ${ }^{10-13}$ However, one of the problems that hinder the application of the plasmas in surface modification of fibers is the cleaning of the resulting effects. After plasma treatments, the fiber surfaces show a gradual hydrophobic recovery over the time and the surface free energy simultaneously decrease to the original value. ${ }^{14-16}$

In this study, we mainly investigated the effect of the ratio of helium/oxygen mixtures, power intensity and treatment time on the wettability of carbon fibers which could be determined using X-ray photoelectron spectroscopy (XPS), scanning electron microscope (SEM), Fourier transform infrared (FT-IR), Zeta-potential, and contact angle measurements. ${ }^{17-19}$

\section{Experimental}

Materials and $\mathrm{He} / \mathrm{O}_{2}$ atmospheric pressure plasma treatment. The atmospheric-pressure plasma surface treatment system employed an ATMOSMulti (PLASMART Co. of Korea). The gases used in the plasma treatments were mixed He $(15 \mathrm{~mL} / \mathrm{min})$ and $\mathrm{O}_{2}(3,5,15 \mathrm{~mL} / \mathrm{min})$. The nominal plasma treatment power was moved to $0 \sim 250 \mathrm{~W}$, and the treatment times, varied between 0 and $30 \mathrm{~s}$ at a radio frequency of $13.56 \mathrm{MHz}$. And the carbon fibers used in this study were untreated and unsized polyacrylonitrile (PAN)-based carbon fibers, TZ-307, manufactured by Taekwang of Korea. A typical modulus for these fibers was about $230 \mathrm{GPa}$.

Surface energetics. The FT-IR instrument used was a Hartman\&Brawm Model Bomen MB 102 spectrophotometer. The scan range was 400 to $4000 \mathrm{~cm}^{-1}$. An X-ray photoelectron spectroscopy (XPS) measurement of fiber surfaces was performed using a LAB MK-II spectrometer equipped with an $\mathrm{MgK} \alpha \mathrm{X}$ ray source (VG Scientific ESCA). In addition, a scanning electron microscope (SEM, JEOL JSM 840A) was used to investigate surface morphologies of the plasma treatment carbon fibers. And the Zeta-potentials were determined using a particle size analyzer (ELS-Z, Otsuka Electronics, Osaka, Japan) at $25^{\circ} \mathrm{C}$ 
Table 1. Surface free energy characteristics of the testing liquids, measured at $20^{\circ} \mathrm{C}$

\begin{tabular}{lccccc}
\hline Wetting liquid & $\gamma_{\mathrm{L}}^{\mathrm{L}}\left(\mathrm{mJ} \cdot \mathrm{m}^{-2}\right)$ & $\gamma_{\mathrm{L}}^{\mathrm{SP}}\left(\mathrm{mJ} \cdot \mathrm{m}^{-2}\right)$ & $\gamma_{\mathrm{L}}\left(\mathrm{mJ} \cdot \mathrm{m}^{-2}\right)$ & $\eta\left(\mathrm{mPa} \cdot \mathrm{s}^{-1}\right)$ & $\rho\left(\mathrm{g} \cdot \mathrm{cm}^{-3}\right)$ \\
\hline$n$-Hexane & 18.4 & 0 & 18.4 & 0.33 & 0.661 \\
Diiodomethane & 50.42 & 0.38 & 50.8 & 2.76 & 3.325 \\
Ethylene glycol & 31.0 & 16.7 & 47.7 & 17.3 & 1.100 \\
\hline
\end{tabular}

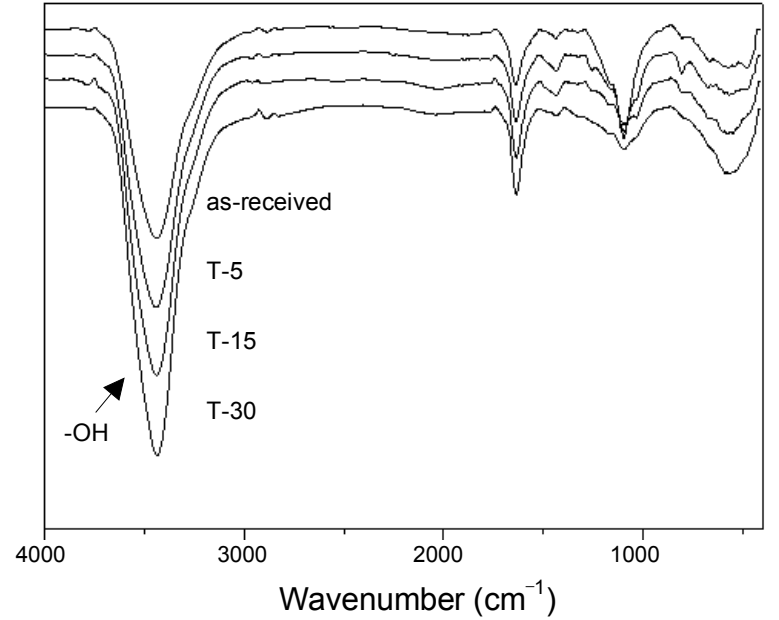

Figure 1. FT-IR spectra of plasma treatment carbon fibers as a function of treatment time.

by diluting the dispersion to an appropriate volume with water.

Contact angle measurements of the carbon fibers were performed using a Krüss Processor Tension meter K100 with a fiber apparatus. Measurements were conducted by packing about $1.5 \mathrm{~g}$ of carbon fibers into the apparatus and then mounting it indirectly to the measuring arm of the microbalance. The packing factor of the carbon fibers was measured for each continuous filament by means of measuring the increase in weight per unit time at zero depth of immersion in a completely wetting liquid. The test wetting liquids of $n$-hexane, diiodomethane, and ethyl glycol were used for contact angle measurements. The surface free energies for the wetting liquids and their London dispersive and specific component are listed in Table $1 .^{20}$

\section{Results and Discussion}

XPS, FT-IR, Zeta-potential, and SEM observation. A XPS analysis was carried out to analyze the elemental composition of the carbon fiber surfaces before and after the plasma treatments. The results are summarized in Table 2. For the plasma treated fibers, the oxygen content increased from $14.8 \%$ to $27.36,30.61$, and $26.33 \%$ for the gas flow ratio $3 / 15,5 / 15$ and $15 / 15$, respectively. However, the amount of oxygen groups is decreased by the gas flow ratio of the treatments up to $15 / 15$. As the ratio approaches to $15 / 15$, it was observed that the generated plasma becomes more unstable. Consequently, the oxygen content on treated the maximum value near $15 / 15$ condition by the excess oxygen matching of plasma more unstable, as is shown in Fig. 2. And the amount of oxygen groups is increased with an increase in the treatment time. Fig. 1 shows the FT-IR measurements of carbon fiber specimens treated by the plasma system.
Table 2. Chemical compositions of the plasma treated carbon fiber surfaces, measured from XPS analysis

\begin{tabular}{|c|c|c|c|c|c|}
\hline \multirow{2}{*}{$\begin{array}{l}\text { Plasma } \\
\text { treatment }\end{array}$} & \multirow{2}{*}{ Time } & \multicolumn{3}{|c|}{ element } & \multirow{2}{*}{$\mathrm{O}_{1 \mathrm{~S}} / \mathrm{C}_{1 \mathrm{~S}}$} \\
\hline & & $\mathrm{C}_{1 \mathrm{~S}}$ & $\mathrm{O}_{1 \mathrm{~S}}$ & $\mathrm{~N}_{1 \mathrm{~S}}$ & \\
\hline \multirow{4}{*}{$\begin{array}{l}\text { Treatment } \\
\text { time }\end{array}$} & As-received & 84.92 & 12.57 & 0.94 & 14.80 \\
\hline & 5 & 83.84 & 13.78 & 1.47 & 16.44 \\
\hline & 15 & 81.90 & 15.33 & 1.70 & 18.72 \\
\hline & 30 & 81.01 & 15.54 & 1.72 & 19.18 \\
\hline \multirow{2}{*}{$\begin{array}{l}\text { Plasma } \\
\text { treatment }\end{array}$} & \multirow{2}{*}{$\mathrm{O}_{2} / \mathrm{He}$} & \multicolumn{3}{|c|}{ element } & \multirow{2}{*}{$\mathrm{O}_{1 \mathrm{~S}} / \mathrm{C}_{1 \mathrm{~S}}$} \\
\hline & & $\mathrm{C}_{1 \mathrm{~S}}$ & $\mathrm{O}_{1 \mathrm{~S}}$ & $\mathrm{~N}_{1 \mathrm{~S}}$ & \\
\hline \multirow{3}{*}{ Gas flow ratio } & $3 / 15$ & 77.99 & 21.34 & 0.68 & 27.36 \\
\hline & $5 / 15$ & 76.07 & 23.29 & 0.63 & 30.61 \\
\hline & $15 / 15$ & 78.26 & 20.61 & 1.10 & 26.33 \\
\hline
\end{tabular}

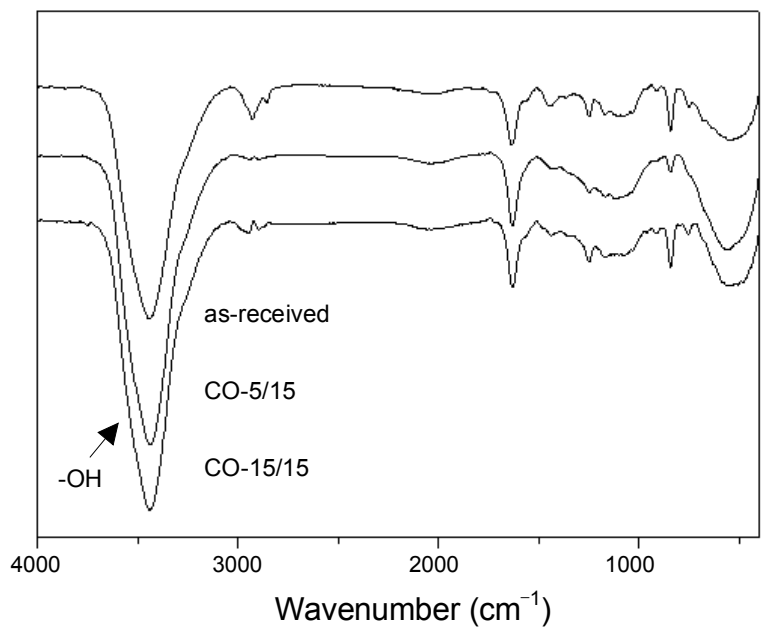

Figure 2. FT-IR spectra of plasma treatment carbon fibers as a function of gas flow ratio.

It is well known that the position of the band for free hydroxyl groups is normally observed around $3500 \mathrm{~cm}^{-1}$. However, the position of the $-\mathrm{OH}$ band in Fig. 1 is shown in the range of $3100 \sim 3600 \mathrm{~cm}^{-1}$. It is a physically adsorbed free -OH functional group, caused by the oxygen plasma treatment. Meanwhile, the intensity of the bands is significantly increased with increasing treatment time. This means that this band is more affected by the $-\mathrm{OH}$ groups made by a plasma treatment, and also indicates that plasma processing increases the oxygen content on the carbon fibers.

Fig. 3 shows significant increases in zeta-potential by plasma treatments. It depicts that zeta-potential values are more affected by the polar hydrophilic functional groups after plasma treat- 


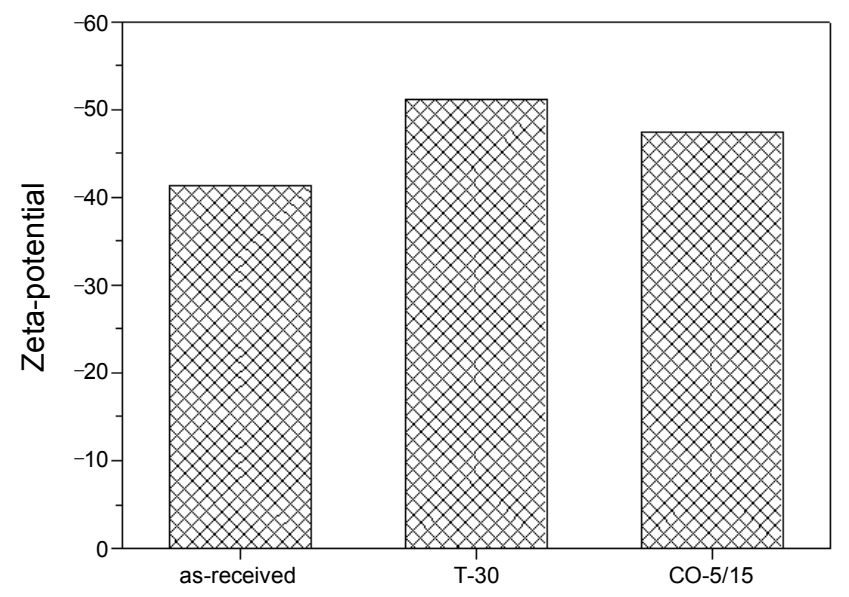

Figure 3. Zeta-potential for as-received, T-30, and CO-5/15 cases.

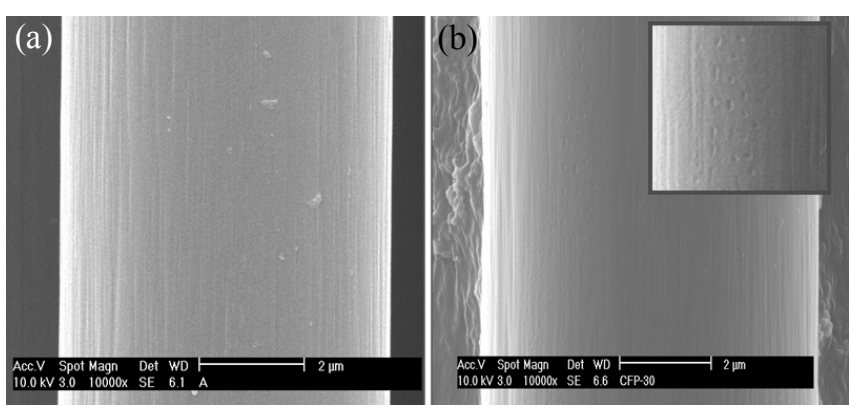

Figure 4. SEM photographs of carbon fibers made with and without plasma surface treatments; (a) as-received and (b) treatment time: 30 sec.

ment. Wettability and dispersion stability of carbon fibers increases by plasma treatment. This result can also be expected from other data from XPS and FT-IR analysis.

Fig. 4 shows SEM micrographs of carbon fibers (a) before and (b) after the plasma treatment. Scanning electron micrographs (10,000 magnifications) of fibers treated $30 \mathrm{~s}$ revealed that plasma treatments did not significantly change surface morphology. Small puddles on the surface appeared after longer treatments as the plasma began etching the fiber surface, but treatment time did not significantly alter the overall fiber diameters.

Contact angle and surface free energy. The wettability of carbon fibers was determined by measuring the wicking rates either by the mass pickup technique or by the surface velocity method. The contact angle used in this investigation was then calculated using Washburn's equation, ${ }^{21}$ which defines the flow of a liquid through a capillary,

$$
\frac{\mathrm{m}}{\mathrm{t}}=\frac{\mathrm{c} \cdot \rho_{2} \cdot \gamma_{\mathrm{L}} \cdot \cos \theta}{2 \eta}
$$

where $\mathrm{m}$ the weight of the penetrating liquid, $\mathrm{t}$ the flow time, $c$ the packing factor, $\gamma_{L}$ surface tension of liquid, $\theta$ the contact angle, and $\eta$ and the liquid density and viscosity, respectively.

The London dispersive and specific components of surface free energy of carbon fibers are determined by measuring the

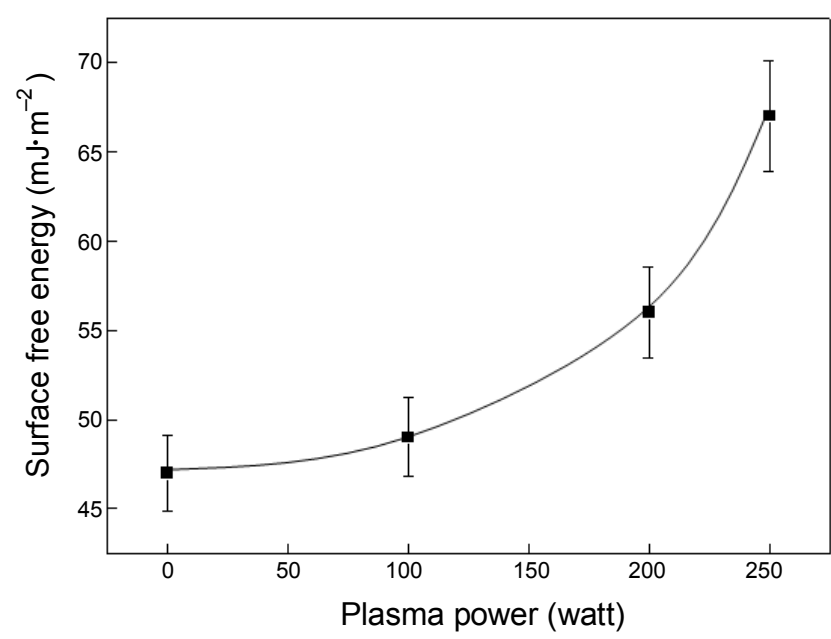

Figure 5. Surface free energy measurements of the plasma treatment carbon fibers by contact angle method.

contact angles of a variety of testing liquids with known London dispersive and specific components and analyzing the results in accordance with the method proposed by Owens and Wendt ${ }^{22}$ and Kaelble, ${ }^{23}$ using the geometric mean.

$$
\frac{\gamma_{\mathrm{L}}(1+\cos \theta)}{2\left(\gamma_{\mathrm{L}}^{\mathrm{L}}\right)^{1 / 2}}=\left(\gamma_{\mathrm{S}}^{\mathrm{SP}}\right)^{1 / 2} \cdot\left(\frac{\gamma_{\mathrm{L}}^{\mathrm{SP}}}{\gamma_{\mathrm{L}}^{\mathrm{L}}}\right)^{1 / 2}+\left(\gamma_{\mathrm{S}}^{\mathrm{L}}\right)^{1 / 2}
$$

where the subscripts $\mathrm{L}$ and $\mathrm{S}$, respectively, represent the liquid and solid states, $\gamma_{\mathrm{L}}^{\mathrm{L}}$ the London dispersive, and $\gamma_{\mathrm{L}}^{\mathrm{SP}}$ the specific component.

The variation of surface energetic of carbon fibers obtained from the angle measurements was illustrated in Fig. 5. It was observed that surface free energy could be dramatically changed with plasma treatment in this system. This behavior can be explained by the improving of the oxygen surface functional groups after plasma treatment, seen in Table 2. This indicates that plasma treatment on carbon fibers leads to an increase in the surface free energy, mainly by its specific component of the surface studied.

In this study, the improved wettability of the carbon fibers was attributed to the surface chemical composition change due to plasma-induced chemical reactions as detected by surface free energy, XPS, SEM, Zeta-potential, and FT-IR analysis. From which, the plasma surface oxidative reactions, such as, generation and combination of the radicals and active oxygen species in this system are believed to have occurred in improving the degree of adhesion at interfaces between fibers and matrix in a composite system. ${ }^{24,25}$

\section{References}

1. Schwartz, M. M. In Composite Materials Handbook; 2nd ed.; McGraw- Hill: New York, 1992.

2. Smith, W. S. In Engineered Materials Handbook; ASM International: Ohio, 1987.

3. Donnet, J. B.; Bansal, R. C. In Carbon Fibers; 2nd ed.; Marcel Dekker: New York, 1990.

4. Chu, J. M.; Lee, E. K.; Choi, S. Y. Elastomer 2008, 43, 113. 
5. Shin, J. W.; Jeun, J. P.; Kang, P. H. J. Ind. Eng. Chem. 2009, 15, 555.

6. Jung. T. Y.; Lim. H. B. Bull. Korean Chem. Soc. 2006, $27,373$.

7. Jensen, C.; Zhang, C.; Qiu, Y. Compos. Interfaces. 2003, 10, 277.

8. Kingsley, K. C. H.; Adam F. L.; Steven, L.; Alexander, B. Composites Part A 2008, 39, 364.

9. Hartney, M. A.; Hess, D.W.; Soane, D. S. J. Vac. Sci. Technol. B 1989, 7,1

10. Park, S. J.; Lee, E. J.; Kwon, S. H. Bull. Korean Chem. Soc. 2007, 30,6 .

11. Park, S. J.; Kim, B. J. J. Colloid Interface Sci. 2004, 275, 590.

12. Montes-Moran, M. A.; Vanhattum, F. W. J.; Nunes, J. P.; MartinezAlonso, A.; Tascon, J. M. D.; Bernardo, C. A. Carbon 2005, 43, 1795.

13. Li, H.; Liang, H.; He, F.; Huang, Y.; Wan, Y. Surf. Coat. Technol. 2009, 203, 1317.
14. Jensen, C.; Zhang, C.; Qiu, Y. Compos. Interfaces 2003, 10, 277.

15. Lawton, R. A.; Price, C. R.; Runge, A. F.; Doherty, W. J.; Saavedra, S. S. Colloid. Surface. A 2005, 253, 213.

16. Dellavolpe, C.; Fambri, L.; Fenner, R.; Migliaresi, C.; Pegoretti, A. J. Mater. Sci. 1994, 29, 3919.

17. Park, S. J.; Jung, W. Y. J. Colloid Interface Sci. 2002, $250,93$.

18. Hwang, Y. J.; McCord, M. G.; Kang, B. C. Fibers Polym. 2005, 6, 113.

19. Gardner, S. D. C.; Singamsetty, S. K.; Booth, G. L.; He, G. R.; Pittman, C. U. Carbon 1995, 33, 587.

20. Park, S. J.; Hsu, J. P. In Interfacial Forces and Fields; Theory and Applications; Dekker: New York, 1999.

21. Washburn, E. W. Phys. Rev. 1921, 17, 273.

22. Owens, D. K.; Wendt, R. C. J. Appl. Polym. Sci. 1969, 13, 1741.

23. Kaelble, D. H. J. Adhes. 1970, 2, 66.

24. Park, S. J.; Kim, B. J. Mater. Sci. Eng. A 2005, 408, 269.

25. Paiva, M. C.; Bernardo, C. A.; Nardin, M. Carbon 2000, 38, 1323. 